\title{
Inoculation with selenobacteria and arbuscular mycorrhizal fungi to enhance selenium content in lettuce plants and improve tolerance against drought stress
}

\author{
P. Durán ${ }^{1 *}, J_{. J}$ Acuña ${ }^{1}$, E. Armada ${ }^{2}$, O.M. López-Castillo², P. Cornejo ${ }^{1}$, M.L. Mora ${ }^{1}$ \\ and R. Azcón, $\mathrm{R}^{2}$ \\ ${ }^{I}$ Scientific and Technological Bioresource Nucleus, Universidad de La Frontera, Avda. Francisco Salazar \\ 01145, Teтuco, Chile. ${ }^{2}$ Departamento de Microbiología del Suelo y Sistemas Simbióticos, Estación \\ Experimental del Zaidin, CSIC, Prof. Albareda 1, 18008 Granada, Spain. * Corresponding author: paola. \\ duran@ufrontera.cl,
}

\begin{abstract}
This study evaluated the co-inoculation effect of the endophytic selenobacteria Bacillus sp., Klebsiella sp. or Acinetobacter sp. and the arbuscular mycorrhizal (AM) fungus Rhizophagus intraradices on lettuce plants grown under drought conditions. Plants inoculated with both microorganisms were able to enhance the Se content in their shoots ( 1 to $6 \mu \mathrm{g} \mathrm{plant}^{-1}$ ) and promote macro-and micronutrient uptake. Moreover, the inoculated plants showed significant tolerance to drought stress, as determined by their adaptation to physiological parameters (relative water content and stomatal conductance),increase in photosynthetic pigments (chlorophyll and carotenoids) and improvement inantioxidant enzyme levels (catalase, ascorbate peroxidase and glutathione reductase). The selenobacteria increased the Se content in lettuce plants and enhanced the effect of AM fungus in controlling the antioxidant systems that play a role as elicitors of plant drought responses and improving the nutritional quality and physiological and biochemical processes involved in plant drought tolerance.
\end{abstract}

Keywords: Antioxidant enzymes, microbial inoculants, nutrient uptake, photosynthetic pigments

\section{Introduction}

Lettuce (Lactuca sativa) is one of the most widely consumed vegetables due to its high mineral content, enhanced cholesterol metabolism and antioxidant properties (Nicolle et al. 2004). Drought stress is a significant obstacle to current crop productivity. Water limitation in plants tends to decrease $\mathrm{CO}_{2}$ influx through stomatal closure (SC), which prevents water loss with a consequent increase of relative water content (RWC).Although photosynthesis provides the organic compounds for plant development, drought affects the photosynthetic rate through stomatal conductance (Meloni et al. 2003) and other physiological changes, including direct damage to the photosynthetic apparatus. Chlorophylls and 
carotenoids are important components of energy metabolism for almost all green plant systems, and the content of these components decreases as a consequence of drought stress (Kumar et al. 2011). Electrolyte leakage (EL) also indicates the status of cellular membranesen during stress conditions (Agami, 2014); plants with high EL suffer from marked drought stress (Zakery-Asl et al. 2014), and the disruption of physiological parameters caused by biotic or abiotic stress leads to the production of toxic reactive species (ROS) that can damage vital plant molecules (Mittler et al. 2004). Therefore, the level of plant drought tolerance can reflect a cascade of complex physiological and biochemical mechanisms. Soil microorganisms known as plant growthpromoting bacteria (PGPB) and arbuscular mycorrhizal (AM) fungi increase nutrient acquisition and plant biomass production. In addition, both can improve antioxidant systems (Durán et al. 2013) and consequently stimulate plant tolerance to abiotic stresses such as drought (Kohler et al. 2009). Several studies have reported that co-inoculation with both microorganisms is particularly effective in increasing the physiological and biochemical values of plants undergoing stress (Armada et al. 2014). The photosynthetic performance of PGPB inoculated plants increased, thus indicating the microbial influence on photosynthetic machinery (Gururani et al. 2013). In addition, microorganisms with PGPB capacity have been recently used for selenium (Se) biofortification with certain bacteria called selenobacteria that can reduce inorganic Se to elemental Se nanospheres (NanoSe) and other important organic Se forms (Acuña et al. 2013; Durán et al. 2013; Durán et al. 2014; Durán et al. 2015). Selenium is an important micronutrient involved in the prevention of oxidative damage (Mora et al. 2008), as it is an essential component in the enzyme glutathione peroxidase and other selenoproteins (Gladyshev et al.
1998). Several studies have reported on the ability of Se to diminish the incidence of different types of cancer formation and progression (Rayman, 2007).

Based on these previous reports, this study hypothesizes that endophytic PGP selenobacteria, interacting with AM fungi, can enhance the Se content in lettuce plants, thus improving drought tolerance and increasing plant growth and the nutritional content of this important agricultural plant species.

\section{Material and Methods}

\subsection{Soil plant bioassay, inoculum preparation and experimental design}

The chemical soil parameters are shown in Table 1. The soil was sieved ( $2 \mathrm{~mm}$ ) and sterilized for 3 consecutive days by means of steam flux. It was then mixed with vermiculite and sand (1:2:2 v:v:v) that was previously autoclaved. Lettuce seeds were disinfected with a sodium hypochlorite solution ( $1 \% \mathrm{w}$ : v) for $5 \mathrm{~min}$, thoroughly washed with distilled water and sown in pots (500 g) containing $0.5 \mathrm{~kg}$ of substrate.

Klebsiella sp E.2, Bacillus sp. E5 and Acinetobacter sp. E6.2 were isolated from biofortified wheat selenium plants (Durán et al. 2014). Endophytic bacteria were grown in Luria Bertani media (LB) with and without (control) sodium selenite for $24 \mathrm{~h}$ at $30{ }^{\circ} \mathrm{C}$ with continuous shaking $(150 \mathrm{rpm})$. Bacterial cells were collected according to Duran et al. (2013) and used as selenobacteria inocula. Pots were inoculated twice, at 14 and 30 days after sowing. In addition, 5 grams of soil containing roots colonized with $70 \%$ Rhizophagus intraradices having 30 spores $\mathrm{g}^{-1}$ were inoculated into each pot in the mycorrhizal treatments, and 5 grams of sterilized soil were included into the non-mycorrhizal control treatments.

A completely randomized experimental design was used where $1 \mathrm{~mL}$ of bacterial inocula containing $10^{9}$ 
$\mathrm{CFU} \mathrm{mL} \mathrm{m}^{-1}$ was injected into the lettuce rhizosphere of each pot. The treatments consisted of (1) a non-inoculated control, (2) Klebsiella sp. E2, (3) Klebsiella sp. E2 grown in selenite, (4) Bacillus sp. E5, (5) Bacillus sp. E5 grown in selenite, (6) Acinetobacter sp. (6) E6.2 and (7) Acinetobacter sp. E6.2 grown in selenite. All treatments were applied to both mycorrhizal and non-mycorrhizal plants. Five replicates per treatment were used.

Table 1. Chemical parameters of the soil used in the bioassay

\begin{tabular}{lr}
\hline \multicolumn{1}{c}{ Variable } & Value \\
\hline $\mathrm{pH}($ water 1:5, w:v) & 8.2 \\
Organic matter (\%) & 1.8 \\
$\mathrm{~N}\left(\mathrm{~g} \mathrm{~kg}^{-1}\right)$ & 2.5 \\
$\mathrm{P}\left(\mathrm{NaHCO}_{3}^{-}\right.$extractable, $\left.\mathrm{g} \mathrm{kg}^{-1}\right)$ & 6.2 \\
$\mathrm{~K}\left(\mathrm{~g} \mathrm{~kg}^{-1}\right)$ & 13.2 \\
\hline
\end{tabular}

\subsection{Mycorrhizal colonization determination}

Mycorrhizal colonization was measured after the clearing of washed roots in $10 \% \mathrm{KOH}$ for $48 \mathrm{hrs}$, acidification in $1 \% \mathrm{HCl}$ for $24 \mathrm{hrs}$ and staining with $0.05 \%$ Trypan blue in lactic acid $(\mathrm{v} / \mathrm{v})$ for $24 \mathrm{hrs}$, according to Phillips and Hayman (1970). Quantification of the root colonization was performed according to the grid-line intersect method (Giovannetti and Mosse, 1980) using a magnification of 100-400X.

\subsection{Plant growth conditions}

Plants were grown in a greenhouse for 4 months under a day/night cycle of $16 / 8 \mathrm{~h}, 21 / 15^{\circ} \mathrm{C}$ and $50 \%$ relative humidity. The range of photosynthetic photon flux density (PPFD) was $1100-500 \mu \mathrm{mol} \mathrm{m} \mathrm{m}^{-2} \mathrm{~s}^{-1}$. Water loss was compensated by watering every day to reach $50 \%$ of water-holding capacity (WHC). Thus, the soil moisture in the pots was measured every 24 $\mathrm{h}$ and water was added to reach a maximum of $50 \%$ WHC. However, during the 24-h period between each re-watering, the soil water content was progressively decreased to a minimum value of $40 \% \mathrm{WHC}$ according to Ortiz et al. (2015). Soil moisture was measured with an ML2 X ThetaProbe (AT Delta-T Devices Ltd, Cambridge, UK), which measured volumetric soil moisture content by responding to changes in the apparent dielectric constant of moist soil (Allen and Allen et al. 1986).

\subsection{Physiological parameters measurements}

At harvest, plants were separated by shoot and root, and the fresh biomass and water content (in an aliquot) were determined. In addition, a portion of the shoot tissue was separated in $0.5 \mathrm{~g}$ aliquots and frozen in liquid nitrogen for further determination of antioxidant enzymatic activities.

\subsubsection{Leaf relative water content}

The leaf relative water content (RWC) was calculated in the plants as follows (Aroca et al. 2003):

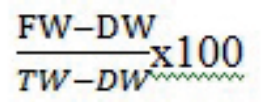

where $\mathrm{FW}=$ fresh weight, $\mathrm{DW}=$ dry weight, and $\mathrm{TW}=$ turgid weight. 


\subsubsection{Stomatal conductance}

Stomatal conductance (SC) was measured using a porometer system (Porometer AP4, Delta-T Devices Ltd, Cambridge, UK). Stomatal conductance measurements were taken in the second fully developed young leaf of each plant at midday the day before harvest. Plants were watered early in the morning to restore $50 \% \mathrm{WHC}$, and $\mathrm{SC}$ measurements were performed at midday.

\subsubsection{Electrolyte leakage}

Leaf samples were thoroughly washed with deionized water to remove surface-adhered electrolytes and were placed in closed vials containing $10 \mathrm{~mL}$ of deionized water and incubated at $25{ }^{\circ} \mathrm{C}$ on a rotary shaker for $24 \mathrm{~h}$. The electrical conductivity of the solution $\left(L_{0}\right)$ was determined using Seven Easy conductivity (Metler Toledo AG 8603, Switzerland). Samples were then autoclaved at $120{ }^{\circ} \mathrm{C}$ for $20 \mathrm{~min}$ and the final electrical conductivity $\left(L_{\mathrm{f}}\right)$ was obtained after cooling at $25{ }^{\circ} \mathrm{C}$. The electrolyte leakage was defined as follows: $\left(\mathrm{L}_{0}-\mathrm{L}_{\text {water }}\right) /\left(\mathrm{L}_{\mathrm{f}}-\mathrm{L}_{\text {water }}\right)$ x 100 , where $\mathrm{L}_{\text {water }}$ was the conductivity of the deionized water used to incubate the samples.

\subsubsection{Leaf photosynthetic pigment contents}

Photosynthetic pigments (chlorophyll a, chlorophyll $\mathrm{b}$ and carotenoids) were extracted by using 100\% methanol from $2 \mathrm{~g}$ of fresh leaf samples. Extinction coefficients and equations reported by Lichtenthaler (1987) were used to calculate the pigment concentrations.

\subsection{Antioxidant enzymatic activities (SOD, CAT, $A P X, G R)$}

Plant shoot samples were homogenized as described by Aroca et al. (2003). Total superoxide dismutase activity (SOD, EC 1.15.1.1) was measured on the basis of the ability to inhibit the reduction of nitroblue tetrazolium (NBT) by photochemically generated superoxide radicals (Burd et al., 2000). One unit of SOD was defined as the amount of enzyme required to inhibit the reduction rate of NBT by $50 \%$ at $25^{\circ} \mathrm{C}$. Catalase activity (CAT, EC 1.11.1.6) was measured as described by Aebi (1984) and was determined as the consumption of $\mathrm{H}_{2} \mathrm{O}_{2}$ (extinction coefficient of 39.6 $\mathrm{mM}^{-1} \mathrm{~cm}^{-1}$ at $240 \mathrm{~nm}$ ). Ascorbate peroxidase activity (APX, EC 1.11.1.11) was measured according to Amako et al. (1994). Glutathione reductase activity (GR, EC 1.20.4.2.) was estimated by measuring the decrease of absorbance at $340 \mathrm{~nm}$ due to the oxidation of NADPH (Carlberg and Mannervik, 1985). The results were expressed in $\mu \mathrm{mol}$ NADPH oxidized mg${ }^{1}$ protein $\mathrm{min}^{-1}$, and the activity was calculated from the initial speed of reaction and the molar extinction coefficient of NADPH $\left(\varepsilon_{340}=6.22 \mathrm{mM}^{-1} \mathrm{~cm}^{-1}\right)$. The total soluble protein amount was determined according to the Bradford method (Bradford, 1976) and useding BSA as the standard.

\subsection{Macro- and micronutrients and Se concentrations}

Shoot macronutrient concentrations for $\mathrm{K}, \mathrm{Ca}$ and $\mathrm{Mg}$ were determined by flame photometry and for $\mathrm{P}$ by a colorimetric procedure (Olsen and Dean, 1965). The micronutrients were also measured by plasma atomic emission spectrometry, and the shoots were then placed in a forced-air oven for two days at $70^{\circ} \mathrm{C}$. 


\subsection{Statistical analyses}

The data were subjected to a general linear model ANOVA (analysis of variance) by using the SPSS v.21 software package for Windows (SPSS Inc.).

The Duncan's (Duncan, 1955) multiple-range test was used for posthoc analysis to determine the differences between means. Differences were considered significant at $p \leq 0.05$.

\section{Results}

\subsection{Nutrient acquisition by inoculated lettuce plants}

The lettuce plants were effectively colonized by the mycorrhiza inoculum (28-42\%). However, Acinetobacter sp. showed lowervalues of approximately $15 \%$ colonization. Our results generally showed a positive effect of endophytic selenobacteria on foliar macronutrient and micronutrient concentrations in lettuce shoots. Moreover, these nutrient levels were higher in plants inoculated with bacteria than in the single-colonized mycorrhizal plants (Table 2).

Table 2. Macro- and micronutrient concentrations in shoots of Se-biofortified lettuce plants

\begin{tabular}{|c|c|c|c|c|c|c|c|c|c|c|c|c|c|c|}
\hline & \multicolumn{2}{|c|}{ Control } & \multicolumn{4}{|c|}{ Bacillus sp. } & \multicolumn{4}{|c|}{ Klebsiella sp. } & \multicolumn{4}{|c|}{ Acinetobacter sp. } \\
\hline $\begin{array}{c}\text { Macronutrients } \\
\left(\mathrm{g} \mathrm{kg}^{-1}\right)\end{array}$ & ct & $\mathrm{ct}+\mathrm{AM}$ & ct & $\mathrm{AM}$ & $\mathrm{Se}$ & AMSe & ct & AM & $\mathrm{Se}$ & AMSe & ct & AM & $\mathrm{Se}$ & AMSe \\
\hline Phosphorous (P) & $2.40^{\mathrm{d}}$ & $3.2^{\mathrm{c}}$ & $3.1^{\mathrm{c}}$ & $4.1^{\mathrm{b}}$ & $3.3^{\mathrm{bc}}$ & $4.4^{\mathrm{b}}$ & $3.9^{\mathrm{b}}$ & $3.5^{\mathrm{bc}}$ & $5.7^{\mathrm{a}}$ & $4.3^{\mathrm{b}}$ & $4.8^{\mathrm{ab}}$ & $3.4^{\mathrm{c}}$ & $3.2^{\mathrm{c}}$ & $2.5^{\mathrm{d}}$ \\
\hline Potassium (K) & $11.6^{\mathrm{d}}$ & $12.8^{\mathrm{d}}$ & $18.2^{\mathrm{bc}}$ & $13.7^{\mathrm{d}}$ & $24.1^{\mathrm{a}}$ & $17.2^{\mathrm{cd}}$ & $21.3^{\mathrm{bc}}$ & $24.7^{\mathrm{ab}}$ & $20.5^{\mathrm{b}}$ & $24.3^{\mathrm{abc}}$ & $17.9^{\mathrm{c}}$ & $17.1^{\mathrm{c}}$ & $19.5^{\mathrm{bc}}$ & $13.1^{\mathrm{d}}$ \\
\hline Calcium (Ca) & $2.50^{\mathrm{d}}$ & $2.37^{\mathrm{d}}$ & $4.17^{\mathrm{bc}}$ & $2.55^{\mathrm{d}}$ & $5.63^{\mathrm{a}}$ & $3.09^{\mathrm{c}}$ & $4.28^{\mathrm{b}}$ & $5.01^{\mathrm{b}}$ & $4.56^{\mathrm{b}}$ & $3.30^{\mathrm{c}}$ & $3.04^{\mathrm{cd}}$ & $3.37^{\mathrm{c}}$ & $4.60^{\mathrm{b}}$ & $3.05^{\mathrm{cd}}$ \\
\hline Magnesium (Mg) & $1.2^{\mathrm{f}}$ & $1.2^{\mathrm{f}}$ & $0.9^{\mathrm{g}}$ & $1.4^{\mathrm{fg}}$ & $1.2^{\mathrm{f}}$ & $2.3^{\mathrm{d}}$ & $1.4^{\mathrm{f}}$ & $1.7^{\mathrm{e}}$ & $1.3^{\mathrm{f}}$ & $9.7^{\mathrm{a}}$ & $2.5^{\mathrm{d}}$ & $1.6^{\mathrm{fg}}$ & $4.8^{\mathrm{c}}$ & $8.4^{\mathrm{b}}$ \\
\hline \multicolumn{15}{|l|}{$\begin{array}{c}\text { Micronutrients } \\
\left(\mathrm{mg} \mathrm{kg}^{-1}\right)\end{array}$} \\
\hline Manganese (Mn) & $24.9^{\mathrm{d}}$ & $22.6^{\mathrm{d}}$ & $45.9^{\mathrm{b}}$ & $23.1^{\mathrm{d}}$ & $56.5^{\mathrm{a}}$ & $28.8^{\mathrm{cd}}$ & $47.4^{\mathrm{b}}$ & $24.9^{\mathrm{d}}$ & $46.0^{\mathrm{b}}$ & $28.5^{\mathrm{cd}}$ & $30.7^{\mathrm{cd}}$ & $27.9^{\text {cd }}$ & $48.4^{\mathrm{b}}$ & $23.4^{d}$ \\
\hline Iron $(\mathrm{Fe})$ & $29.8^{\mathrm{f}}$ & $26.4^{\mathrm{f}}$ & $143.5^{\mathrm{bc}}$ & $61.6^{\text {def }}$ & $117.6^{\mathrm{bc}}$ & $47.7^{\mathrm{d}}$ & $112.9^{\mathrm{b}}$ & $89.2^{\mathrm{c}}$ & $191.8^{\mathrm{a}}$ & $33.6^{\mathrm{f}}$ & $34.0^{\mathrm{ef}}$ & $50.5^{\mathrm{d}}$ & $51.5^{\mathrm{d}}$ & $32.1^{\mathrm{f}}$ \\
\hline Copper $(\mathrm{Cu})$ & $2.55^{\mathrm{c}}$ & $3.34^{b c}$ & $2.60^{\mathrm{c}}$ & $5.49^{\mathrm{a}}$ & $2.64^{\mathrm{bc}}$ & $2.54^{\mathrm{c}}$ & $2.84^{\mathrm{bc}}$ & $5.37^{\mathrm{a}}$ & $3.00^{\mathrm{bc}}$ & $2.87^{\mathrm{b}}$ & $3.17^{\mathrm{b}}$ & $1.78^{\mathrm{d}}$ & $3.15^{\mathrm{bc}}$ & $1.83^{\mathrm{d}}$ \\
\hline Zinc ( $\mathrm{Zn})$ & $6.51^{\mathrm{de}}$ & $9.83^{\mathrm{bc}}$ & $13.2^{\mathrm{a}}$ & $13.0^{\mathrm{a}}$ & $9.79^{\mathrm{bc}}$ & $6.13^{\mathrm{de}}$ & $7.13^{\mathrm{cd}}$ & $10.2^{\mathrm{b}}$ & $5.61^{\mathrm{e}}$ & $7.82^{\mathrm{cd}}$ & $8.48^{\mathrm{c}}$ & $6.84^{\mathrm{d}}$ & $8.06^{\mathrm{cd}}$ & $5.28^{\mathrm{e}}$ \\
\hline
\end{tabular}

Abbreviations: ct: control; Bacillus sp. (ct: control, AM: Rhizophagus intraradices, Se: Se biosynthesized by bacteria, AMSe: R. intraradices + Se biosynthesized by bacteria) Klebsiella sp. (ct: control, AM: Rhizophagus intraradices, Se: Se biosynthesized by bacteria, AMSe: $R$. intraradices + Se biosynthesized by bacteria) Acinetobacter sp. (ct: control, AM: Rhizophagus intraradices, Se: Se biosynthesized by bacteria, AMSe: $R$. intraradices + Se biosynthesized by bacteria) 


\subsubsection{Macronutrients ( $\mathrm{P}, \mathrm{K}, \mathrm{Ca}, \mathrm{Mg}$ )}

Plants inoculated with endophytic selenobacteria showed significant macronutrient acquisition compared to the non-inoculated plants $(\mathrm{Ct})$ and the mycorrhizal plants without bacteria (AM) (Table 2). The mycorrhizal plants showed higher $\mathrm{P}$ acquisition than the control plants (3.2 and $2.4 \mathrm{~g} \mathrm{~kg}^{-1}$, respectively). This effect was significant when the plants were inoculated with endophytic selenobacteria (Table 2). Significant correlations between $\mathrm{P}$ and $\mathrm{K}(\mathrm{r}=0.628, p \leq 0.05)$ and $\mathrm{Mg}$ and $\mathrm{Ca}(\mathrm{r}=0.802, p \leq 0.05)$ were found. As for biomass production, no differences were found between the control and mycorrhizal plants (Figure 1), whereas plants inoculated with bacteria showed significant biomass production, primarily in shoots rather than roots.

\subsubsection{Micronutrients ( $\mathrm{Mn}, \mathrm{Fe}, \mathrm{Cu}, \mathrm{Zn})$}

Plants inoculated with bacteria showed significant micronutrient concentrations compared to plants without bacteria (Table 2). No effect was found in mycorrhizal plants without bacteria except in the case of Zinc ( $\mathrm{Zn}$ ), where mycorrhizal plants showed significant $\mathrm{Zn}$ content compared to the control (9.83 and $6.51 \mathrm{mg} \mathrm{kg}^{-1}$, respectively).

Most of the micronutrient concentrations were enhanced in the inoculated plants, except for $\mathrm{Cu}$. $\mathrm{Cu}$ was directly related to the $\mathrm{Mn}$ content in the plants $(p<0.05)$, where its content did not vary from mycorrhizal to non-mycorrhizal plants.

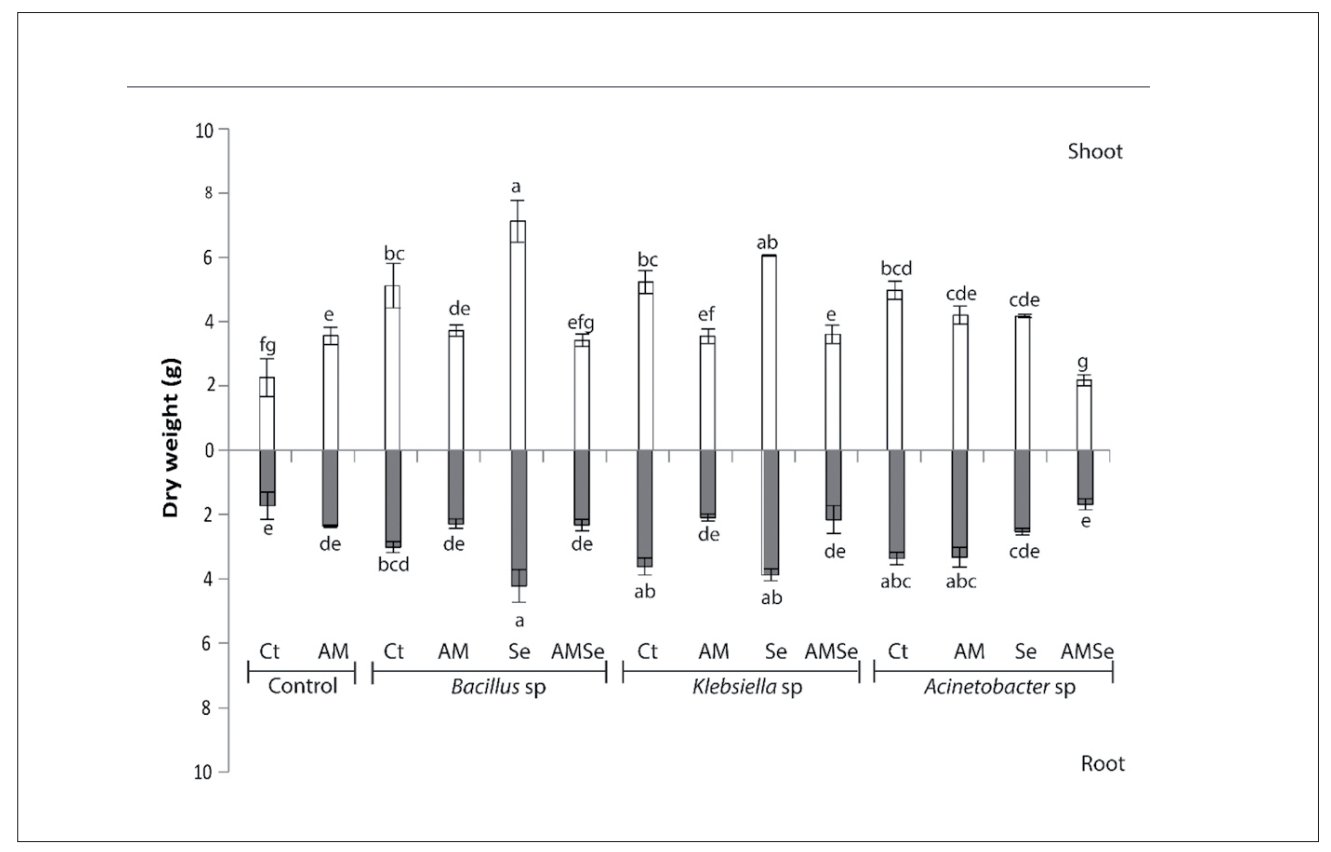

Figure 1. Biomass production (dry weight) of lettuce plants inoculated with endophytic selenobacteria (B) and/or the arbuscular mycorrhizal fungus (m) Rhizophagus intraradices with Se (Se) and without $\mathrm{Se}$ supplementation. Values having a common letter are not significantly different $(p \leq 0.05)$ according to Duncan's multiple-range test $(n=3)$. 


\subsection{Total Se content in inoculated lettuce plants}

Significant Se concentrations in were found in the roots and shoots of wheat plants (Figure 2).

Plants inoculated with Klebsiella sp. showed the most significant Se concentrations in both shoots and roots compared to the other selenobacteria strains. No differences between the mycorrhizal and non-mycorrhizal plants were found. In the roots, plants inoculated exclusively with $R$. intraradices showed less Se than plants inoculated with bacteria, except for Acinetobacter sp., where no significant differences were found.

\subsection{Physiological response of Se-supplemented lettuce plants}

The applied drought stress caused a reduction in RWC in the control lettuce plants (Figure 3A). No significant differences in RWC were observed in the mycorrhizal plants; however, when plants were inoculated with Bacillus sp. and Acinetobacter sp., the RWC index was significantly enhanced. In the plants inoculated with Klebsiella sp., no significant differences were found, but the RWC index was significantly enhanced when the plants were supplemented with Se. In particular, lettuce plants inoculated with Bacillus sp. showed a higher RWC.

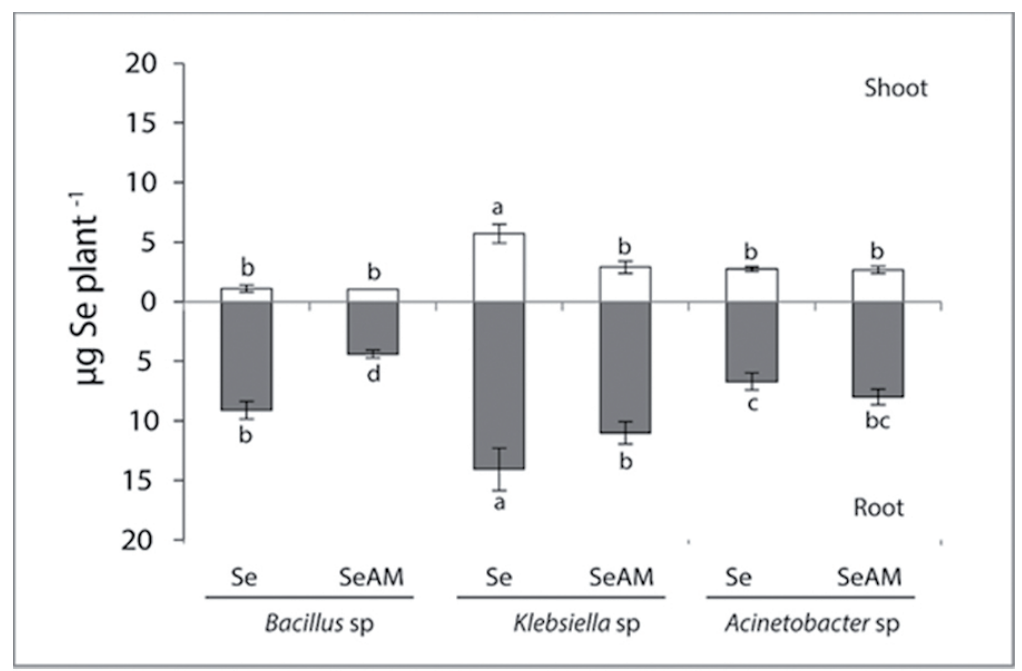

Figure 2. Selenium accumulation $\left(\mu \mathrm{g}\right.$ plant $\left.^{-1}\right)$ in roots and shoots of lettuce plants inoculated with endophytic selenobacteria and the arbuscular mycorrhizal fungus $(\mathrm{m})$ Rhizophagus intraradices grown under drought conditions. Values having a common letter are not significantly different $(p \leq 0.05)$ according to Duncan's multiplerange test $(n=3)$. 


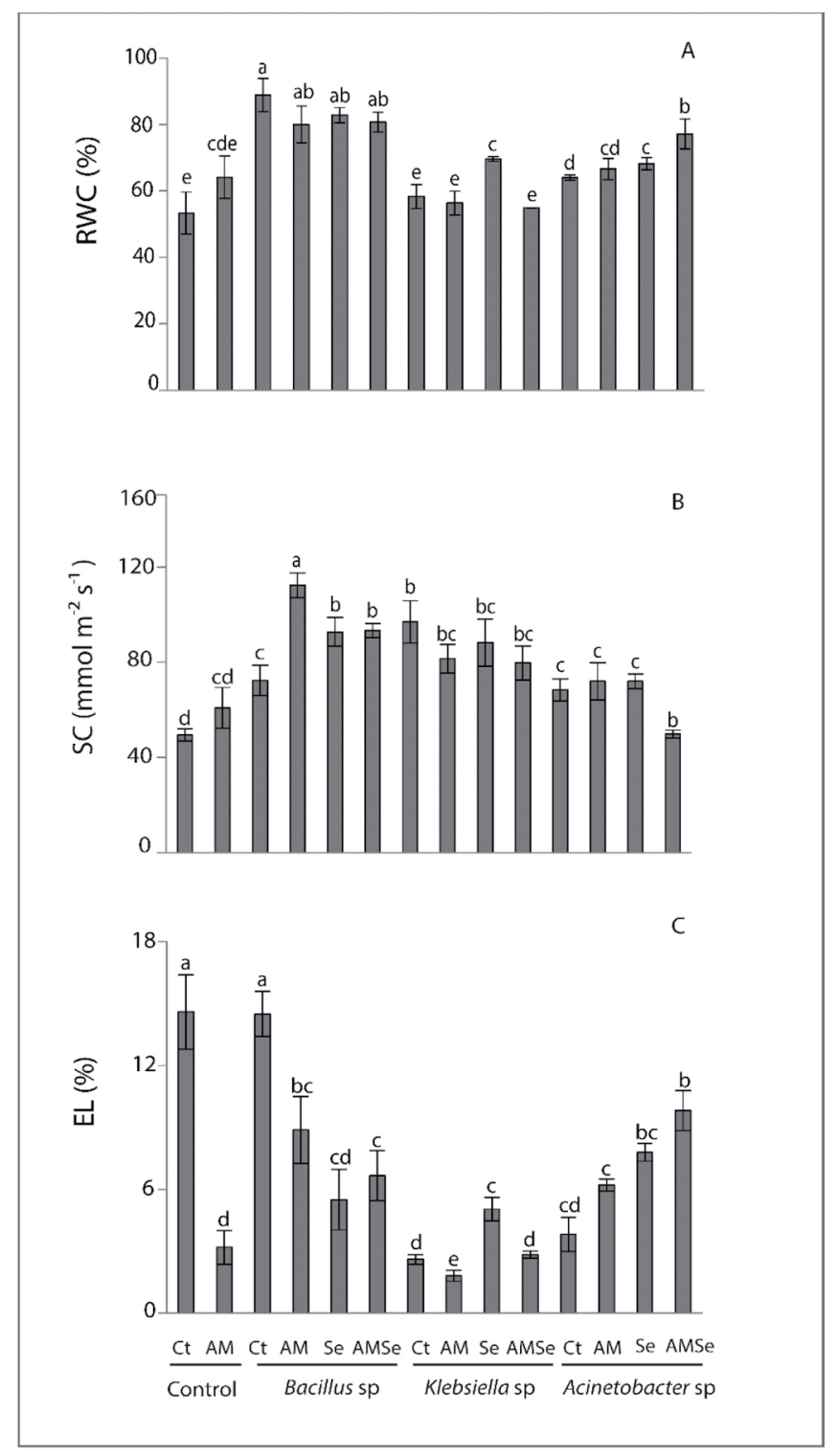

Figure 3. A) Relative water content (RWC); B) stomatal conductance (SC) and C) electrolyte leakage (EL), on lettuce plants inoculated with endophytic selenobacteria (B) and/or the arbuscular mycorrhizal fungus (m) Rhizophagus intraradices grown under drought conditions, with $\mathrm{Se}(\mathrm{Se})$ and without Se supplementation. Within each graph, values having a common letter are not significantly different $(\mathrm{p} \leq 0.05)$ according to Duncan's multiple-range test $(\mathrm{n}=3)$. 
Plants inoculated with endophytic selenobacteria showed a significantly higher SC index compared to non-inoculated plants (Figure 3B); no significant differences were found in mycorrhizal plants without bacteria. Plants inoculated with Bacillus sp. showed significantly higher SC values than when exposed to the other treatments. Similarly, the EL index, which shows the intactness of cellular plasma membranes, was lower in the inoculated plants compared to the control (Figure 3C).
As for the leaf photosynthetic pigment contents (chlorophyll a, chlorophyll b, total chlorophyll and carotenoids), the lettuce plants inoculated with endophytic selenobacteria or mycorrhiza showed increased levels of these physiological parameters (Figure 4). This effect was not found in plants solely inoculated with single Bacillus sp., but these contents were enhanced in the presence of Se, mycorrhiza and to a greater extent, both treatments (AMSe).

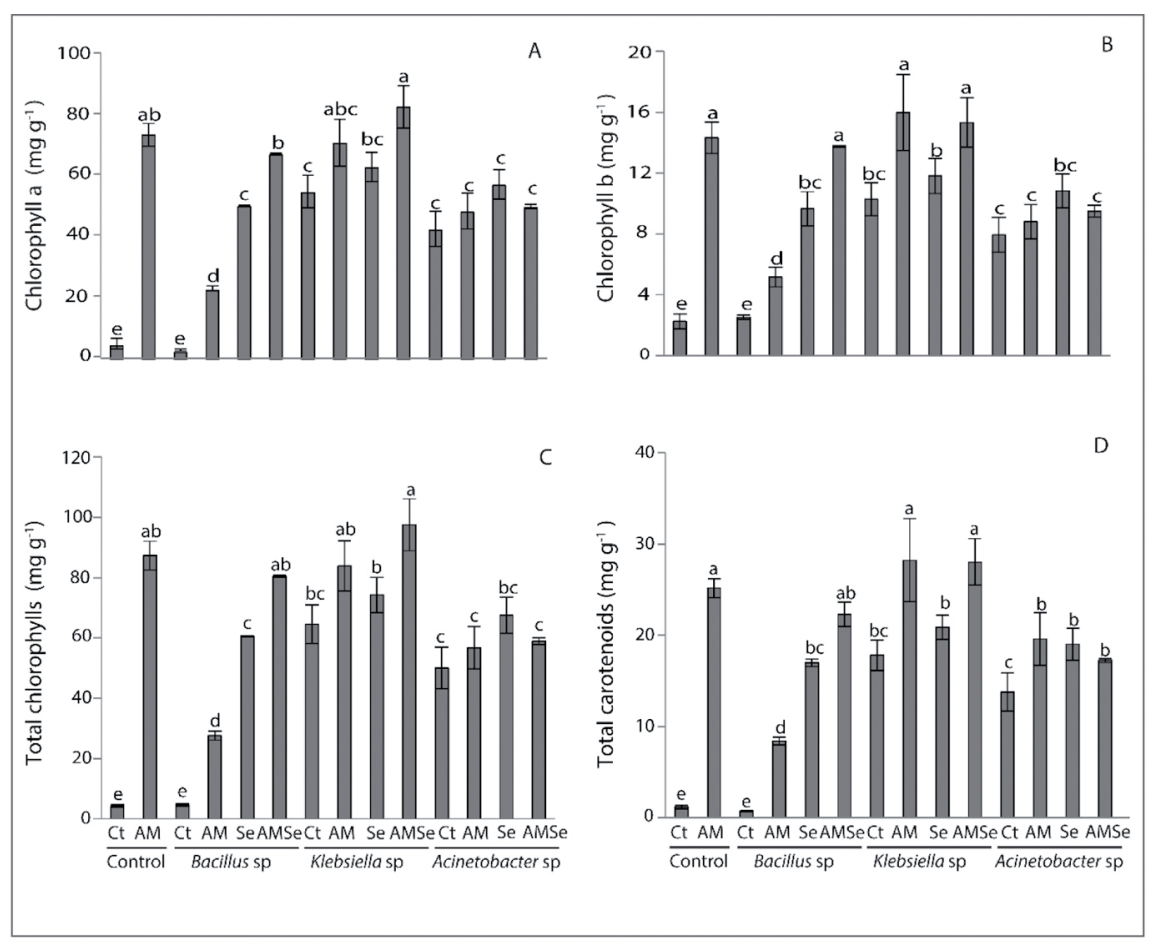

Figure 4. Leaf photosynthetic pigment contents: A) chlorophyll a, B) chlorophyll b, C) chlorophyll total and C) carotenoids, on lettuce plants inoculated with endophytic selenobacteria arbuscular and/or the arbuscular mycorrhizal fungus (m) Rhizophagus intraradices grown under drought conditions with $\mathrm{Se}(\mathrm{Se})$ and without Se supplementation. Within each graph, values having a common letter are not significantly different $(\mathrm{p} \leq 0.05)$ according to Duncan's multiple-range test $(n=3)$. 


\subsection{Antioxidant enzymatic response ( $S O D, C A T, A P X, G R$ )}

Mycorrhizal plants inoculated with Acinetobacter sp., with and without Se (Se and AMSe), and treatments without bacteria inoculation (AM) showed significant SOD activity compared to the other treatments (Figure 5A). Similarly, plants inoculated only with
Klebsiella sp. showed elevated SOD values. Elevated CAT activity was observed in the most of the treatments compared to the control (Figure 5B). As for APXand GR enzymatic activities, the endophytic selenobacteria inoculated lettuce plants were able to significantly increase these activities in comparison to the mycorrhizal plants (Figure 5C, D).

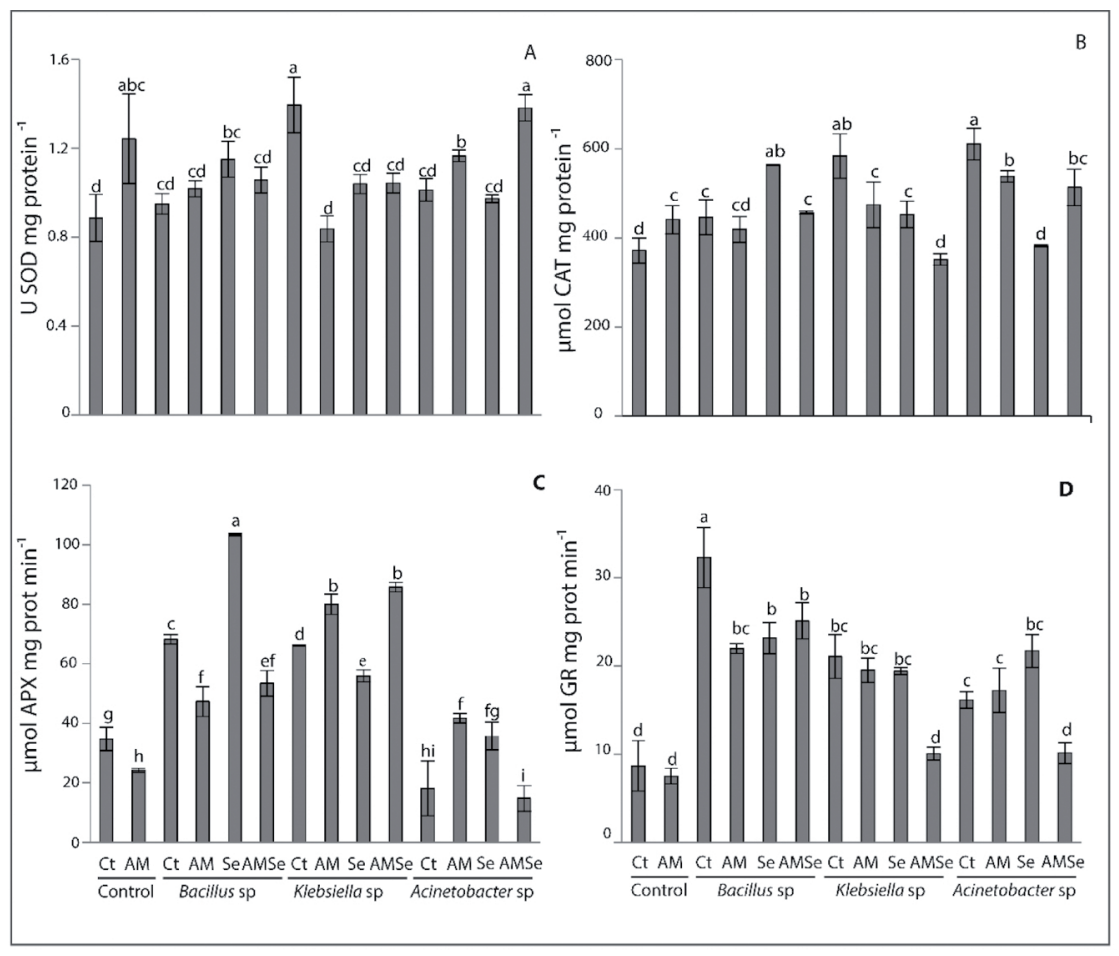

Figure 5. Antioxidant activity: A) Superoxide dismutase (SOD), B) Catalase (CAT), C) Ascorbate peroxidase (APX) and D) Glutathione reductase (GR) on lettuce plants inoculated with endophytic selenobacteria and/ or the arbuscular mycorrhizal fungus (m) Rhizophagus intraradices grown under drought conditions, with Se (Se) and without Se supplementation. Within each graph, values having a common letter are not significantly different $(p \leq 0.05)$ according to Duncan's multiple-range test $(\mathrm{n}=3)$. 


\section{Discussion}

In this study, three endophytic selenobacteria, Bacillus sp., Klebsiella sp. and Acinetobacter sp., were supplemented with Se and inoculated into lettuce plants in consortia with Rhizophagus intraradices to determine the effects of co-inoculation in Se biofortification and mitigation of drought stress. The lettuce plants displayed a higher level of biomass production when inoculated with endophytic selenobacteria. According to our results, the bacteria were more efficient than the AM fungus in terms of biomass production, which was directly correlated with macronutrient uptake $(\mathrm{Ca}, \mathrm{K}, \mathrm{Mg}$ and $\mathrm{P})$. In particular, $\mathrm{P}$ levels were increased in the presence of AM colonization, as had been previously reported by Heap (1980). However, K was an important element in alleviating water stress and was able to protect the chloroplasts from oxidative damage and affect root water acquisition (Porras-Soriano et al. 2009; Romheld and Kirkby, 2010). Similarly, significant micronutrients were found in the inoculated plants with bacteria and/or AM in comparison to the control lettuce plants. Bacteria are known to release metal-chelating substances such as iron-chelating siderophores. Previous studies have shown that these bacteria strains are siderophore producers (Durán et al., 2014). Siderophore-producing bacteria influence the plant uptakes of various metals such as $\mathrm{Fe}, \mathrm{Zn}$ and $\mathrm{Cu}$ (Dimkpa et al. 2009).

As for the Se concentrations, no significant differences were found between the mycorrhizal and non-mycorrhizal plants, in concordance with previous studies by the same authors (unpublished data) in wheat plants. Reinforcing studies carried out with rhizospheric bacteria showed that AMcolonized wheat plants were more efficient in Se uptake and incorporation (Durán et al. 2013) and was attributed to the endophytic characteristic of the bacteria, which can enter the root cells with Nano Se (unpublished data). In our study, Se concentrations in the shoots (comestible organ) ranged between 1 to 6 $\mu \mathrm{g}$ plant $^{-1}$. According to the Recommended Dietary Allowances (RDAs), $55 \mu \mathrm{g} \mathrm{Se}$ day $^{-1}$ is an adequate dose for preventing disease (Thiry et al. 2012).Thus, Se-biofortified lettuce could effectively complement Se nutrition in humans.

Microbial inoculation also improved some of the physiological parameters evaluated in this study. Plants inoculated with both endophytic bacteria and/ or AMF improved RWC by means of increasing SC $(\mathrm{r}=0.322, \mathrm{p} \leq 0.05)$. This higher $\mathrm{SC}$ index could produce an enhanced photosynthesis rate (Tanaka et al. 2013) through an increase in photosynthetic pigments such as chlorophyll a, b and carotenoids (Mena-Violante et al. 2006). In this sense, carotenoids play an important role due to their pro-vitamin A activity, and their antioxidant potential may increase the function of the immune system and inhibit the development of some types of cancers (Maiani et al. 2009). Consequently, the lower electrolytic leakage in the inoculated plants indicates that the microbial inoculated treatments are able to maintain a gas exchange capacity under drought conditions and decrease the membrane damage in these plants; low electrolyte leakage is an indicator of cell membrane stability and tolerance to hydric stress (Berglund et al. 2004). However, the role of Se in improving net photosynthesis under drought stress was not demonstrated, in contrast to results by Wang et al. (2011) and Diao et al. (2014), who reported an increase in net photosynthesis when inorganic Se was supplied.

Studies show that the drought stress enhances the activity of antioxidant enzymes in scavenging for toxic ROS (Kim et al. 2012; Kasim et al. 2013).Here, microbially inoculated plants (primarily with bacteria) 
increased APX, CAT and GR, which may indicate the protective role of these inoculants on lettuce for reducing ROS under drought stress. However, SOD activity was not accompanied by an increase in these enzymes as $\mathrm{H}_{2} \mathrm{O}_{2}$ scavenging. The overall results indicate that bacterially inoculated plants are well protected against drought stress but the coordination between the antioxidants is complex, as reported by Mittler et al. (2004). Despite inorganic Se being related to the alleviation of drought stress (Wang et al. 2011), this study found no effect of Se biosynthesized by bacteria, similar to other studies realized by our research group (dates not published).

Our results suggest that microbial inoculants, primarily endophytic PGP selenobacteria, improve plant quality and protect against drought stress conditions (Medina and Azcón, 2010). Therefore, their use can improve the nutritional value of lettuce by enhancing the Se content in edible tissue and simultaneously counteract the effect of drought stress by maintaining physiological parameters and scavenging reactive oxygen species. The arbuscular mycorrhizal colonization increased the acquisition of macronutrients, particularly $\mathrm{P}$, and increased the antioxidant response of the host plant. Therefore, the use of endophytic bacteria inoculant alone or in combination with effective AM strains is suggested as a tool for Se biofortification in order to contribute to sustainable agriculture.

\section{Acknowledgments}

This study was supported by the Comisión Nacional de Investigación Científica y Tecnológica (CONICYT), FONDECYT Postdoctoral Project $N^{\circ} 3130542$ from the Chilean Government and project reference AGL200912530-C02-02 (Spain Government). E. Armada was financed by the Ministry of Science and Innovation (Spain). The authors appreciate the technical support of the Scientific and Technological Bioresource Nucleus
(BIOREN) from La Frontera University and Estación Experimental del Zaidín, from Consejo Superior de Investigaciones Científicas (CSIC).

\section{References}

Acuña, J.J., Jorquera, M.A., Barra, P.J., Crowley, D.E., Mora, M.L. 2013. Selenobacteria selected from the rhizosphere as a potential tool for Se biofortification of wheat crops. Biol. Fertil. Soils. 49, 175-185.

Aebi, H. 1984. Catalase in vitro. Methods Enzymol. $105,121-126$

Agami, R.A. 2014. Applications of ascorbic acid or proline increase resistance to salt stress in barley seedlings. Biol. Plant. 58, 341-347.

Allen, E.B., Allen, M.F. 1986.Water relations of xeric grasses in the field: interactions of mycorrhizas and competition. New Phytol. 104, 559-571.

Amako, K., Chen, G.X., and Asada, K. 1994. Separate assays specific for ascorbate peroxidase and guaiacol peroxidase and for the chloroplastic and cytosolic isozymes of ascorbate peroxidase in plants. Plant Cell Physiol. 35, 497-504.

Armada, E., Roldán, A., Azcón, R. 2014. Differential activity of autochthonous bacteria in controlling drought stress in native Lavandula and Salvia plants species under drought conditions in natural arid soil. Microb. Ecol. 67, 410-420.

Aroca, R., Irigoyen, J.J., Sánchez-Díaz, M. 2003. Drought enhances maize chilling tolerance. II. Photosynthetic traits and protective mechanisms against oxidative stress. Physiol Plant. 117, 540-549.

Berglund, A.H., Larsson, K.E., Liljenberg, C.S. 2004. Permeability behaviour of lipid vesicles prepared from plant plasma membranes : impact of compositional changes. BBA-Mol. Cell. Biol. L. 1682, 11-17. 
Bradford, M.M. 1976. Rapid and sensitive method for quantitation of microgram quantities of protein utilizing principle of protein-dye binding. Anal. Biochem. 72, 248-254.

Burd, G.I., Dixon, D.G., Glick, B.R. 2000. Plant growth promoting bacteria that decreased heavy metal toxicity in plants. Can. J. Microbiol. 46, 237-245.

Carlberg, I.. Mannervik, B. 1985. Glutathione reductase. Methods Enzymol. 113, 484-489.

Diao, M., Ma, L., Wang, J., Cui, J., Fu, A., Liu, H.Y. 2014.Selenium promotes the growth and photosynthesis of tomato seedlings under salt stress by enhancing chloroplast antioxidant defense system. J. Plant Growth Regul. 33, 671682.

Dimkpa, C.O., Merten, D., Svatos, A., Buechel, G., Kothe, E. 2009. Siderophores mediate reduced and increased uptake of cadmium by Streptomyces tendae F4 and sunflower (Helianthus annuиs), respectively. J. Appl. Microbiol. 107, 1687-1696.

Duncan, D.B. 1955. Multiple range and multiple F tests. Biometrics. 11, 1-42

Durán, P., Acuna, J.J., Jorquera, M.A., Azcon, R., Borie, F., Cornejo, P., Mora, M.L. 2013. Enhanced selenium content in wheat grain by co-inoculation of selenobacteria and arbuscular mycorrhizal fungi: A preliminary study as a potential $\mathrm{Se}$ biofortification strategy. J. Cereal Sci. 57, 275280.

Durán, P., Acuna, J.J., Jorquera, M.A., Azcon, R., Paredes, C., Rengel, Z., Mora, M.L. 2014. Endophytic bacteria from selenium-supplemented wheat plants could be useful for plant-growth promotion, biofortification and Gaeumannomyces graminis biocontrol in wheat production. Biol. Fertil. Soils. 50, 983-990.
Durán, P., Acuna, J.J., Gianfreda, L., Azcón, R., Funes-Collado, V., Mora, M.L. 2015. Endophytic selenobacteria as new inocula for selenium biofortification. Appl. Soil Ecol. Accepted.

Giovannetti, M., Mosse, B. 1980. Evaluation of techniques for measuring vesicular arbuscular mycorrhizal infection in roots. New. Phytol. 84, 489-500

Gladyshev, V.N., Jeang, K.T., Wootton, J.C., Hatfield, D.L. 1998. A new human selenium-containing protein : Purification, characterization, and cDNA sequence. J. Biol. Chem. 273, 8910-8915.

Gururani, M.A., Upadhyaya, C.P., Baskar, V., Venkatesh, J., Nookaraju, A., Park, S.W. 2013. Plant growth-promoting rhizobacteria enhance abiotic stress tolerance in Solanum tuberosum through inducing changes in the expression of ROS-scavenging enzymes and improved photosynthetic performance. J. Plant Growth Regul. 32, 245-258.

Heap, A., Newman, E.I. 1980. The influence of vesicular-arbuscular mycorrhizas on phosphorous transfer between plants. New Phytol. 85, 173- 179.

Kasim, W.A., Osman, M.E., Omar, M.N., Abd ElDaim, I.A., Bejai, S., Meijer, J. 2013. Control of drought stress in wheat using plant-growthpromoting bacteria. J. Plant Growth Regul. 32, 122-130.

Kim, H.J., Khalimonchuk, O., Smith, P.M., Winge, D.R. 2012. Structure, function, and assembly of heme centers in mitochondrial respiratory complexes. Biochim. Biophys. Acta. 1823, 1604-1616.

Kohler, J., Hernández, J.A., Caravaca, F., Roldán, A. 2009.Induction of antioxidant enzymes is involved in the greater effectiveness of a PGPR versus AM fungi with respect to increasing the tolerance of lettuce to severe salt stress. Environ. Exp. Bot. 65, 245-252. 
Kumar, R.R., Karajol, K., Naik, G.R. 2011. Effect of polyethylene glycol induced water stress on physiological and biochemical responses in Pigeonpea (Cajanus cajan L. Millsp.). Recent. Res. Sci. Tech.148-152.

Lichtenthaler, H.K. 1987. Chlorophylls and carotenoids: pigments of photosynthetic biomembranes. Methods Enzymol.148, 350-382.

Maiani, G., Periago Caston, M.J., Catasta, G., Toti, E., Goni Cambrodon, I., Bysted, A., GranadoLorencio, F., Olmedilla-Alonso, B., Knuthsen, P., Valoti, M., Boehm, V., Mayer-Miebach, E., Behsnilian, D., Schlemmer, U. 2009. Carotenoids: Actual knowledge on food sources, intakes, stability and bioavailability and their protective role in humans. Mol. Nutr. Food Res. 53, 194-218.

Medina, A., Azcón, R. 2010. Effectiveness of the application of arbuscular mycorrhiza fungi and organic amendments to improve soil quality and plant performance under stress conditions. J. Soil Sci. Plant Nut. 10, 354-372.

Meloni, D.A., Oliva, M.A., Martinez, C.A., Cambraia, J. 2003. Photosynthesis and activity of superoxide dismutase, peroxidase and glutathione reductase in cotton under salt stress. Environ. Exp. Bot.49, 69-76.

Mena-Violante, H.G., Ocampo-Jiménez, O., Dendooven, L., Martinez-Soto, G., GonzálezCastaneda, J., Davies, F.T., Jr., Olalde-Portugal, V. 2006. Arbuscular mycorrhizal fungi enhance fruit growth and quality of chile ancho (Capsicum annuum L. cv San Luis) plants exposed to drought. Mycorrhiza. 16, 261-267.

Mittler, R., Vanderauwera, S., Gollery, M., Van Breusegem, F. 2004. Reactive oxygen gene network of plants. Trends Plant. Sci. 9, 490-498.

Mora, M.L., Pinilla, L., Rosas, A.. Cartes, P. 2008. Selenium uptake and its influence on the antioxidative system of white clover as affected by lime and phosphorus fertilization. Plant Soil. 303, 139-149

Nicolle, C., Cardinault, N., Gueux, E., Jaffrelo, L., Rock, E., Mazur, A., Amouroux, P., Rémésy, C. 2004. Health effect of vegetable-based diet: lettuce consumption improves cholesterol metabolism and antioxidant status in the rat. Clinical Nutrition, 23 (4), 605-614.

Olsen, S.R. and Dean, L.A. 1965. Phosphorus. In: Methods of Soil Chemical Analysis, C.A. Black, D.D. Evans, J.L. White, L.E. Ensminger, F.E. Clark, and R.C. Dinauer, eds. Madison, WI: American Society of Agronomy. 1035-1049.

Ortiz, N., Armada, E., Duque, E., Roldán, A., Azcón, R. 2015. Contribution of arbuscular mycorrhizal fungi and/or bacteria to enhancing plant drought tolerance under natural soil conditions: Effectiveness of autochthonous or allochthonous strains. J. Plant. Physiol. 174, 87-96.

Phillips, J.M., Hayman, D.S. 1970. Improved procedure of clearing roots and staining parasitic and vesicular-arbuscular mycorrhizal fungi for rapid assessment of infection. Trans. Br. Mycol. Soc., 55, 159-161.

Porras-Soriano, A., Soriano-Martin, M.L., PorrasPiedra, A. Azcón, R. 2009.Arbuscular mycorrhizal fungi increased growth, nutrient uptake and tolerance to salinity in olive trees under nursery conditions. J Plant Physiol.166, 1350-1359.

Rayman, M.P. 2007. Selenium in cancer prevention: a review of the evidence and mechanism of action. Proc. Nutr. Soc. 64, 527-542.

Romheld, V., Kirkby, E.A. 2010. Research on potassium in agriculture: needs and prospects. Plant Soil. 335, 155-180. 
Tanaka, Y., Sugano, S. S., Shimada, T., HaraNishimura, I. 2013. Enhancement of leaf photosynthetic capacity through increased stomatal density in Arabidopsis. New Phytologist. 198, 757-764

Thiry, C., Ruttens, A., De Temmerman, L., Schneider, Y.J., Pussemier, L. 2012. Current knowledge in species-related bioavailability of selenium in food. Food Chem., 130, 767-784.
Wang, C.-Q., Xu, H.-J., Liu, T. 2011. Effect of selenium on ascorbate-glutathione metabolism during PEG-induced water deficit in Trifolium repens L. J. Plant Growth Regul. 30, 436-444.

Zakery-Asl, M.A., Bolandnazar, S. Oustan, S. 2014. Effect of salinity and nitrogen on growth, sodium, potassium accumulation, and osmotic adjustment of halophyte Suaeda aegyptiaca (Hasselq.) Zoh. Arch. Agron. Soil. Sci. 60, 785-792. 